
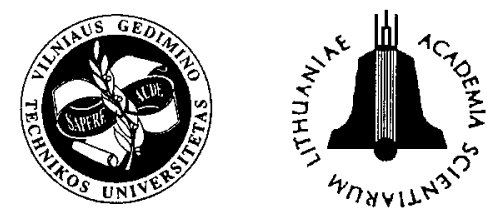

JOURNAL OF CIVIL ENGINEERING AND MANAGEMENT

http:/Www.vtu.lt/english/edition

2002, Vol VIII, No 2, 121-124

\title{
DETERMINATION OF THERMAL-MECHANICAL PROPERTIES OF CONCRETE
}

\author{
Ramiz Delpak ${ }^{1}$, Albinas Gailius², Dangyras Žukauskas ${ }^{3}$ \\ ${ }^{1}$ Reader in Civil Engineering, School of Technology, University of Glamorgan, \\ Pontypridd CF37 ID, UK. E-mail: rdelpak@glam.ac.uk \\ ${ }^{2,3}$ Dept of Building Materials, Vilnius Gediminas Technical University, Sauletekio al. II, \\ LT-2040Vilnius, Lithuania; ${ }^{2}$ E-mail: stsm@st.vtu.lt; ${ }^{3}$ E-mail: dangyrasz@yahoo.com
}

Received 15 March 2001; accepted 05 Febr 2002

\begin{abstract}
The aim of this investigation was to find the relationship between different percentagc of damage and thermal conductivity of concrete. The influence of different damage on thermal conductivity of concrete was determined. The method with insulation (ordinary method) based on the temperature difference measurement between two surfaces of specimen, when one of the surfaces is heated, was used for thermal conductivity measurement. Three specimens for every percentage of damage were used for each measurement of thermal conductivity. After this research one conclusion can be made definitely: influence of different percentage of damage on thermal conductivity of concrete.
\end{abstract}

Keywords: compressive strength, concrete, damage, non-destructive testing, structure, thermal conductivity.

\section{Introduction}

Concrete structure may be damaged due to construction errors, environmental exposure, and service loads. This damage should be non-destructively detected and characterised in a timely and reliable fashion. Scarcity of funds needed for repair or replacement of all structurally deficient or functionally obsolete concrete structures forces the state agencies to search for advanced non-destructive testing (NDT) techniques which will facilitate rapid, cost efficient and reliable condition assessment of existing infrastructure to ensure public safety [1]. Incorporation of the quantitative results of NDT techniques in infrastructure management systems is expected to provide the needed feedback in monitoring for detection and identification of deficiencies, and setting up priorities for repair, retrofitting or replacement actions. In recent years, numerous studies have been reported giving application examples of non-destructive testing techniques when detecting and locating anomalies in concrete. Infrared techniques are commonly used in military applications, NDT of materials and medical diagnosis. Infrared thermography can be used to locate and determine the extent of voids in concrete [1]. This method is based on the principle that subsurface anomalies in a material result in localised differences in surface temperature caused by different rates of heat transfer at the defect zones. However, the heat transfer mechanism pertaining to the detection process has not theoretically been analysed. It is necessary to simulate the detection process by applying an appropriate physical model based on the real phe- nomena [2]. Temperature variation detection can help detect that physical model.

The primary goal of any non-destructive evaluation technique is to detect and locate the anomalies within an optically opaque medium through appropriate imaging techniques [1]. In the case of concrete, such techniques are expected to provide information about thickness variations as well as the inclusions such as the crack voids and delaminations, deteriorated zones and moisture.

After loading, various damages and air inclusions are formed in the structure of concrete. It is natural that these changes have an influence on the thermal properties of concrete. It is known that the size and form of air inclusions have a considerable influence on the thermal properties of hard materials when other parameters are the same [3]. Therefore we can assume that concrete will have different thermal properties after different loading.

\section{Materials}

For making concrete Ordinary Portland Cement, class $42.5 \mathrm{~N}$, Blue Circle, UK was used. Properties of the cement are prescribed by British Standard [4]. The coarse aggregate was manufactured from limestone, Aber Kenfic, Quarry. British Standard [5] and researchers [6, 7] prescribe the aggregate properties. The sand was dredged from Bristol Channel, therefore it includes some salt. Generally, sand from the seabed washed even in seawater does not contain harmful quantities of salt. The salt content is limited by British Standard [8]. The sand also contains seashells. This usually has no adverse ef- 
fect on strength but workability of concrete is slightly reduced (British Standard [9]). Sand was sieved by hand through $1.18 \mathrm{~mm}$ sieve before using.

\section{Experimental procedure}

\subsection{Preparation of test specimens}

Dry materials for producing four $100 \times 100 \times 500 \mathrm{~mm}$ size beams were thoroughly mixed in CUMFLOW H1KO4-1526 mixer for 2 min before slowly adding the calculated amount of water. Intermittent hand mixing with hand trowels was necessary to achieve a homogeneous mix. After 5 min of mixing a slump test was carried out for establishing the workability.

The slump test is prescribed in British Standard [10]. The mould for the slump test was a frustum of a cone, $300 \mathrm{~mm}$ high. It was placed on a smooth surface with the smaller opening at the top, and filled with concrete in three layers. Each layer was tamped 25 times with a standard $16 \mathrm{~mm}$ diameter steel rod, rounded at the end, and the top of surface was struck off. The cone was firmly held against its base during the entire operation; this was facilitated by handles or footrests brazed to the mould. Immediately after filling, the cone was slowly lifted, and then the unsupported concrete slumped. The decrease was measured to "displaced original centre". In order to reduce the influence on a slump of the variation in the surface friction, the inside of the mould and its base were moistened at the beginning of every test. Prior to lifting of the mould, the area immediately around the base of the cone was cleaned of concrete, which may have dropped accidentally. When the mix had a zero slump the water was added to obtain a slump within $30-$ $60 \mathrm{~mm}$, mixed again for 3-5 min and the test repeated. A slump of $30 \mathrm{~mm}$ was obtained. Amount of materials required for workability test and slump results are displayed in Table 1.

Table 1. Amount of materials

\begin{tabular}{|l|c|}
\hline \multicolumn{1}{|c|}{ Materials } & Amount, $\mathrm{kg}$ \\
\hline Water & 4.2 \\
\hline Portland cement & 7.6 \\
\hline Sand & 15.2 \\
\hline Coarse aggregate & 30.4 \\
\hline
\end{tabular}

Concrete beams were cast in $100 \times 100 \times 500 \mathrm{~mm}$, steel moulds previously assembled and oiled and placed on a vibration table. Vibration was done immediately after placing the concrete.

To achieve the highest possible density of the concrete, the mortar was vibrated on a vibrating table. Vibration was applied uniformly to the entire concrete mass, as otherwise some parts of it would be not fully compacted while others might be segregated due to overvibration. In order to obtain the concrete with identical properties, all moulds were filled and vibrated together at the same time.
All moulds were cast at the same time. The specimens were remoulded at the age of one day after casting, the specimens were immersed in a water bath for 28 days prior to testing for compressive strength (CS). The temperature of water was $20^{\circ} \mathrm{C} \pm 1{ }^{\circ} \mathrm{C}$. The temperature of curing water could not be much lower than that of the concrete in order to avoid thermal shock or steep temperature gradients; ACI 308-92 recommends a maximum difference of $11^{\circ} \mathrm{C}$.

Cylindrical specimens of $42 \times 81 \mathrm{~mm}$ (Fig l) for thermal conductivity tests were cut from concrete beams of $100 \times 100 \times 500 \mathrm{~mm}$ after the curing period. For specimens cutting Radial Drill R3, Qualters \& Smith, UK was used. Two pits were drilled in each specimen for temperature measurement by the ordinary method.

\subsection{Compression of cylindrical specimens}

The CS of concrete was obtained using the standard method prescribed in British Standard [11]. Specimens were crushed by loading them at a constant rate of stress increase of $18 \mathrm{~N} \mathrm{~mm}^{-2} \mathrm{~min}^{-1}$. Nine cylindrical specimens were used for CS test. Results of CS test are listed in Table 2.

Table 2. Compressive strength of cylindrical specimens

\begin{tabular}{|c|c|c|}
\hline $\begin{array}{c}\text { Number of } \\
\text { specimen }\end{array}$ & $\begin{array}{c}\text { Compressive strength } \\
\mathrm{F}, \mathrm{MN} / \mathrm{m}^{2}\end{array}$ & $\begin{array}{c}\text { Average of compressive } \\
\text { strength, } \mathrm{MN} / \mathrm{m}^{2}\end{array}$ \\
\hline 1 & 34.58 & \\
\hline 2 & 31.19 & \\
\hline 3 & 41.66 & \\
\hline 4 & 27.44 & \\
\hline 5 & 30.61 & 35.00 \\
\hline 6 & 39.42 & \\
\hline 7 & 33.65 & \\
\hline 8 & 40.72 & \\
\hline 9 & 35.74 & \\
\hline
\end{tabular}

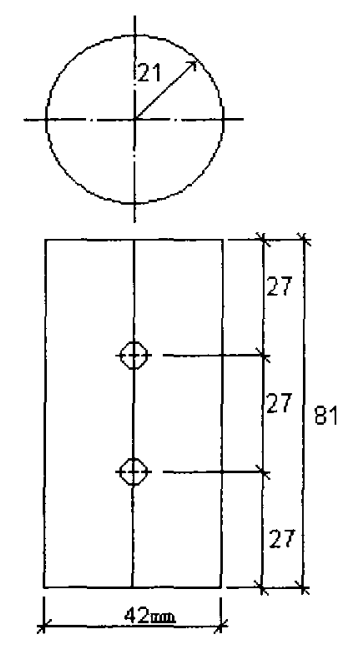

Fig 1. Specimen for thermal conductivity tests 
Others specimens were compressed with different percentage of CS $(35 \%, 50 \%, 75 \%)$. Results are presented in Tables 3, 4 and 5.

Table 3. 35\% compressive load on cylindrical specimens

\begin{tabular}{|c|c|c|c|}
\hline $\begin{array}{c}\text { Number of } \\
\text { specimen }\end{array}$ & $\begin{array}{c}\text { Compressive } \\
\text { load F, } \\
\mathrm{MN} / \mathrm{m}^{2}\end{array}$ & $\begin{array}{c}\text { Average of } \\
\text { compressive load, } \\
\mathrm{MN} / \mathrm{m}^{2}\end{array}$ & $\begin{array}{c}\text { Percentage, } \\
\%\end{array}$ \\
\hline 1 & 12.49 & & \\
\hline 2 & 12.35 & 12.18 & 34.8 \\
\hline 3 & 11.70 & & \\
\hline
\end{tabular}

Table 4. 50\% compressive load on cylindrical specimens

\begin{tabular}{|c|c|c|c|}
\hline $\begin{array}{c}\text { Number of } \\
\text { specimen }\end{array}$ & $\begin{array}{c}\text { Compressive } \\
\text { load F, } \\
\mathrm{MN} / \mathrm{m}^{2}\end{array}$ & $\begin{array}{c}\text { Average of } \\
\text { compressive load, } \\
\mathrm{MN} / \mathrm{m}^{2}\end{array}$ & $\begin{array}{c}\text { Percentage, } \\
\%\end{array}$ \\
\hline 1 & 17.11 & & \\
\hline 2 & 17.62 & 17.42 & 49.8 \\
\hline 3 & 17.55 & & \\
\hline
\end{tabular}

Table 5. 75\% compressive load on cylindrical specimens

\begin{tabular}{|c|c|c|c|}
\hline $\begin{array}{c}\text { Number of } \\
\text { specimen }\end{array}$ & $\begin{array}{c}\text { Compressive } \\
\text { load } \mathbf{F}, \\
\mathrm{MN} / \mathrm{m}^{2}\end{array}$ & $\begin{array}{c}\text { Average of } \\
\text { compressive load, } \\
\mathrm{MN} / \mathrm{m}^{2}\end{array}$ & $\begin{array}{c}\text { Percentage, } \\
\%\end{array}$ \\
\hline 1 & 26.35 & & \\
\hline 2 & 26.35 & 26.35 & 75.3 \\
\hline 3 & 26.35 & & \\
\hline
\end{tabular}

\subsection{Thermal conductivity}

For thermal conductivity determination the ordinary method was used. This method is based on temperature difference measurement between two surfaces of specimen when one of surfaces is heated. The temperature readings were obtained from thermometers.

Thermal conductivity measurement was done in the same direction as loading. Three devices for thermal conductivity determination (Fig 2) were used. For temperature measurement Microcomputer Thermometer, Model ST-7001, SOLEX, Taiwan, was used. Three specimens with different percentage of damage $(0 \%, 35 \%$, $50 \%$ and $75 \%$ ) for every device for thermal conductivity determination were used for each measurement of thermal conductivity. The temperature was measured every half an hour. An average of the ambient temperature was $23^{\circ} \mathrm{C} \pm 2^{\circ} \mathrm{C}$.

\section{Results and discussions}

Fig 3 shows the thermal conductivity obtained by the ordinary method. Each data set is an average of nine test results.

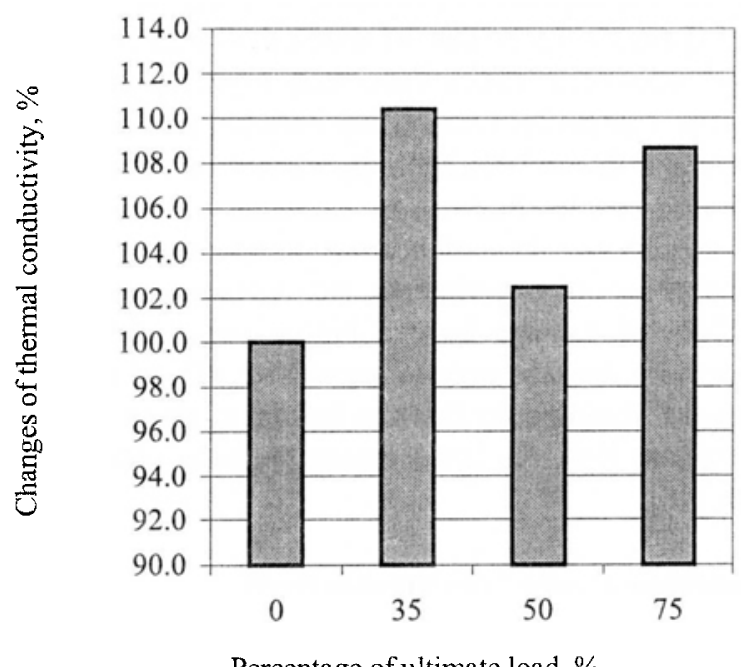

Percentage of ultimate load, $\%$

Fig 3. Changes of thermal conductivity

Formula (1) [12-14] was used for the laboratory thermal conductivity calculation:

$$
k_{L}=\frac{Q}{A} \frac{\Delta X}{\Delta T},
$$

where $Q$ is rate of energy, $A$ is area of heating surface, $\Delta \mathrm{X}$ is distance between points of temperature measurement, $\Delta \mathrm{T}$ is temperature difference.

Because of different factors influence on experimental process it is necessary to take into consideration those factors. That is why for final thermal conductivity calculation formula (2) [15] was used:

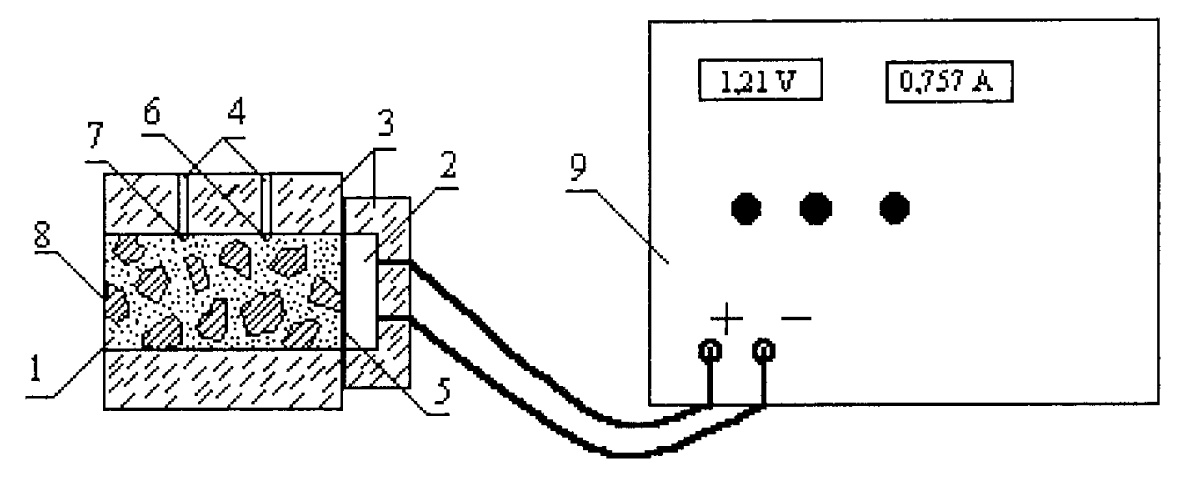

Fig 2. Device for thermal conductivity determination: 1 specimen; 2 heating element; 3 insulation; 4 holes for thermometers; $5,6,7$ and 8 temperature checking points (T1, T2, T3, T4); 9 power supply 


$$
k_{d e c}=k_{L}+\Delta k_{d}+\Delta k_{a}+\Delta k_{\omega h},
$$

where $k_{d e c}$ is thermal conductivity, $k_{L}$ is laboratory thermal conductivity, $\Delta k_{d}$ is deflection of thermal conductivity values, $\Delta k_{a}$ is correction of thermal conductivity due to aging of material, $\Delta k_{\omega h}$ is correction due to hygroscopic dampness.

Specimens with $35 \%$ of damage have a bigger value of thermal conductivity than the non-damaged specimens in all cases. Although the general trend of thermal conductivity was expected to increase to a higher percentage of damage, the results of specimens with $50 \%$ and $75 \%$ of damage are much lower than expected. It means that some continuous relationship between percentage of damage and thermal conductivity cannot be observed in Fig 3. Reasons for that can be character of damages in small specimens, time of heating, temperature of heating, conditions of experiments, etc. Anyway, specimens with $75 \%$ of damage have a bigger value of thermal conductivity than the non-damaged and $50 \%$ of damage specimens. Reasons for that can be that at about $70 \%$ of the ultimate load, the bond cracks begin to increase in length [16].

\section{Conclusions and recommendations}

Concrete is a composite material and different parts of its structure can have different thermal conductivity and it is necessary to find a more representative method for temperature measurement in the ordinary method, because temperature measurement only in one point of surface is not representative enough.

Experimental investigations showed that with different percentage of damage concrete has different thermal conductivity, but for final conclusions it is necessary to repeat experiments using larger specimens with more representative structure, because character of damage depends on the specimen size [16-20].

For further research an investigation to find a more precise method for the temperature control of the heating element is required, because the temperature was measured with $0.1{ }^{\circ} \mathrm{C}$ precision, but at the same time the temperature of the heating element could change by several degrees.

Thermal conductivity measurement was done in the same direction as loading. It is known that the size and form of air inclusions influence greatly the thermal properties of hard materials [3]. Experimental investigations with 90 degrees respect to loading could show different results, because of character of damage and direction of cracks (air inclusions) that are formed in concrete after loading [16].

Experimental data show that relationship between damages and thermal conductivity of concrete exists, and further investigations in this property of concrete can be useful for NTD techniques evaluation and in future can become a precise method for non-distractive concrete testing.

\section{References}

1. Buyukozturk O. Imaging of concrete structures. $N D T \& E$ International, Vol 31. London: Elsevier Science Ltd., 1998, p. $233-243$.

2. Inagaki T., Ishii T., Iwamoto T. On the NDT and E for the diagnosis of defects using infrared thermography. NDT \& E International, Vol 32. London: Elsevier Science Ltd., 1999, p. 247-257.

3. Misnar A. Heat transfer in solid materials, liquids, gas and their composites (Теплопроводность твердых тел, жидкостей, газов и их композиций). Moscow: Mir, 1968. 464 c. (in Russian).

4. BS 12: 1996 Spec. for Portland cements.

5. BS 812: Part 1: 1975 Methods for determination of particle size and shape.

6. Gailius A., Vislavičius K., Žukauskas D. Some optimisation problems of the aggregates composition of concrete. In: Proceedings of $6^{\text {th }}$ international conference "Modern Building Materials, Structures and Techniques", held on May 19-21, 1999, Vilnius, Vol IV. Vilnius: Technika, 1999, p. 158-162 (in Lithuanian).

7. Vislavičius K. General principles of modelling physicalmechanical properties of conglomerates. Civil Engineering (Statyba), Vol VI, No 3. Vilnius: Technika, 2000, p. 175-178 (in Lithuanian).

8. BS 8110: Part 1: 1985 Structural use of concrete: code of practice for design and construction.

9. BS 882: $1992 \mathrm{Spec}$. for aggregates from natural sources for concrete.

10. BS 1881: Part 102: 1983 Method for determination of slump.

11. BS 1881: Part 116: 1983 Method for determination of compressive strength of concrete cubes.

12. Taine J., Petit J.-P. Heat transfer. London: Prentice Hall International Ltd., 1993. 584 p.

13. Chapman A. J. Heat transfer. London: Collier Macmillan Publishers, 1984. $608 \mathrm{p}$.

14. Holman J. P. Heat transfer. Singapore: Keyword Publishing Services Ltd., 1992. 714 p.

15. STR 2.01.03:1999 Declared and design values of thermaltechnical characteristics of building materials and products. Vilnius: Ministry of Environment, 1999 (in Lithuanian).

16. Carpinteri A., Ferro G., Monetto I. Scale effects in uniaxially compressed concrete specimens. Magazine of Concrete Research, Vol 51, No 3. London: Thomas Telford Services Ltd., 1999, p 217-225.

17. Bazant Z. P. Size effect in blunt fracture: concrete, rock, metal. Journal of Engineering Mechanics (ASCE), Vol 110. Reston: ASCE-Amer Soc Civil Engineers, 1984, p. 518-535.

18. Kim J. K., Eo S. H. Size effect in concrete specimens with dissimilar initial cracks. Magazine of Concrete Research, Vol 42. London: Thomas Telford Services Ltd., 1990, p. 233-238.

19. Neville A. M. Properties of concrete. Harlow: Longman Group Limited, 1995. 844 p.

20. Jackson N., Dhir R. K. Civil Engineering Materials. London: Macmillan Press Ltd., 1996. 534 p. 